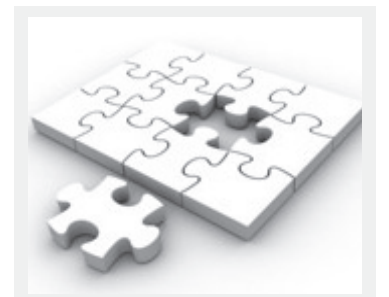

In an effort to facilitate the selection of appropriate peer reviewers for the South African Journal of Communication Disorders, we ask that you take a moment to update your electronic portfolio on www.sajcd.org.za for our files, allowing us better access to your areas of interest and expertise, in order to match reviewers with submitted manuscripts.

If you would like to become a reviewer, please visit the journal website and register as a reviewer.

To access your details on the website, you will need to follow these steps:

1. Log into the online journal at http://www. sajcd.org.za

2. In your 'user home' [http://www.sajcd.org. za/index.php/sajcd/user] select 'edit my profile' under the heading 'my account' and insert all relevant details, bio statement and reviewing interest.

3. It is good practice as a reviewer to update your personal details regularly to ensure contact with you throughout your professional term as reviewer to the South African Journal of Communication Disorders.

Please do not hesitate to contact me if you require assistance in performing this task.

\section{Rochelle Flint} submissions@sajcd.org.za Tel: +27219752602 Fax: +27 219754635

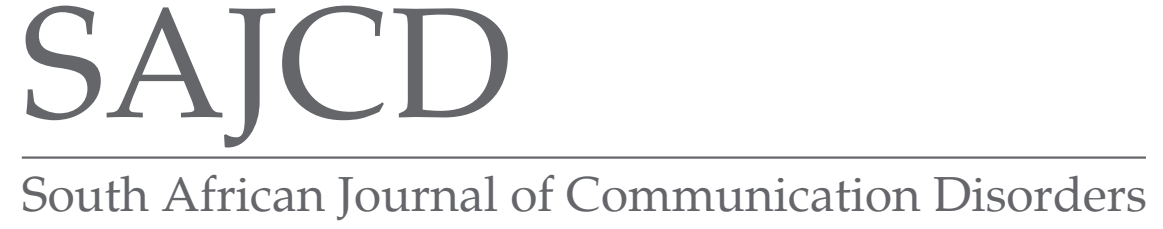

The editorial team of the South African Journal of Communication Disorders recognises the value and importance of peer reviewers in the overall publication process - not only in shaping individual manuscripts, but also in shaping the credibility and reputation of our journal.

We are committed to the timely publication of all original, innovative contributions submitted for publication. As such, the identification and selection of reviewers who have expertise and interest in the topics appropriate to each manuscript are essential elements in ensuring a timely, productive peer review process.

We would like to take this opportunity to thank the following reviewers who participated in shaping this issue of the South African Journal of Communication Disorders:

Alida Ellis
Amisha Kanji
Anna-Mari Olivier
Bea Staley
Christine Rogers
Daleen Klop
Edwin Maas
Fatemah Camroodien-Surve
Guilherme M. de Carvalho
Hannelie Kemp
Hilary Gardner
Jaishika Seedat
Jane le Roux
Jenny Pahl
Joanne Barratt

Karyn Casey

Katherine Vorster

Lebogang Ramma

Luanet Smit

Lucia Scheepers

Maggi Soer

Marinda Uys

Meera Rijhumal

Melissa Bortz

Mershen Pillay

Prawin Kumar

Sue Rumble

Ursula L. Zsilavecz

Zandile Blose

We appreciate the time taken to perform your review successfully. 